\title{
DO DIREITO DE AÇÃO COMO UM MEIO DE ACESSO À JUSTIÇA E DA AUSÊNCIA DE PARÂMETROS LEGAIS PARA CONCESSÃO DOS BENEFICÍOS DA JUSTIÇA GRATUITA
}

Fernanda Agostinho Garcia ${ }^{1}$

Josyane Mansano ${ }^{2}$

GARCIA, F. A.; MANSANO, J. Do Direito de ação como um meio de acesso à Justiça e da ausência de parâmetros legais para concessão dos beneficíos da Justiça gratuita. Rev. Ciênc. Juríd. Soc. UNIPAR. Umuarama. v. 22, n. 2, p. 209-221, jul./dez. 2019.

RESUMO: O presente artigo tem como objetivo discutir e analisar, baseando-se em leis, jurisprudências e casos concretos, a forma como o judiciário tem julgado os pedidos de assistência judiciária gratuita e o conceito de hipossuficiência que se tem aplicado para definir quem tem direito ou não as benesses da justiça gratuita. Além disto, também será trazido à lume, o conceito do Direito constitucional de Ação e sua relação direta com o Acesso à Justiça, baseando-se na Constituição federal, na Lei 9060/50 e no Código de Processo Civil de 2015, o qual trouxe em sua nova redação algumas mudanças sobre a justiça gratuita. Como forma de demonstrar a ausência de uniformidade das decisões sobre o tema, serão citadas jurisprudências de variados estados que divergem entre si, causando insegurança jurídica aos litigantes, fazendo com que as custas processuais se tornem um filtro impeditivo de acesso ao judiciário, causando, por conseguinte, um atentado ao estado democrático.

PALAVRAS-CHAVE: Direito de ação; Acesso à justiça; Justiça gratuita; Hipossuficiência.

\section{THE RIGHT IN ACTION AS A MEANS OF ACCESS TO JUSTICE AND THE ABSENCE OF LEGAL PARAMETERS TO GRANT THE BENEFITS OF FREE LEGAL AID}

\footnotetext{
ABSTRACT: This article aims at discussing and analyzing, based on laws, case law and specific cases, how the judiciary has judged the requests for free legal aid and the concept of hypo-sufficiency that has been applied to define who is

DOI: $10.25110 /$ rcjs.v22i2.2019.7869

${ }^{1}$ Advogada, graduada em Direito pelas Faculdades Maringá. Pós-Graduanda pela UNIFCV. E-mail: garcia@salvadorgarcia.com.br

${ }^{2}$ Doutoranda e Mestre em Direito pela Universidade de Marília. Coordenadora do Curso de Pósgraduação em Direito Lato Sensu da UNIFCV. Docente nos curso de graduação e pós-graduação da UNIFCV. Advogada em Maringá - PR. E-mail: prof_mansano@unifcv.edu.br
} 
entitled or not to the benefits of free legal aid. In addition, the concept of the constitutional Right in Action and its direct relationship with Access to Justice will also be brought to light, based on the Brazilian Federal Constitution, Law 9060/50 and the 2015 Brazilian Code of Civil Procedure, which brought in its new wording some changes about free legal aid. In order to demonstrate the lack of uniformity of decisions on the matter, jurisprudences of various states that differ from each other will be quoted, which cause legal uncertainty to litigants, turning the cost of proceedings into an impeditive filter of access to the judiciary, thus causing an attack on the democratic state.

KEY WORDS: Right in action; Access to justice; Free legal aid; Hyposufficiency.

\section{EL DERECHO DE ACCIÓN COMO MEDIO DE ACCESO A LA JUSTICIA Y DE LA AUSENCIA DE PARÁMETROS LEGALES PARA OTORGAR LOS BENEFICIOS DE LA JUSTICIA GRATUITA}

RESUMEN: Este artículo tiene como objetivo discutir y analizar, con base en las leyes, la jurisprudencia y los casos específicos, cómo el poder judicial ha juzgado las solicitudes de asistencia jurídica gratuita y el concepto de hiposuficiencia que se ha aplicado para definir quién tiene derecho o no a los beneficios de la justicia gratuita. Además, el concepto del derecho de acción constitucional y su relación directa con el acceso a la justicia también saldrán a la luz, el concepto del Derecho Constitucional de Acción y su relación directa con el Acceso a la Justicia, basándose en la Constitución Federal, en la Ley 9060/50 y en el Código de Procedimiento Civil de 2015, que trajo consigo en su nueva redacción algunos cambios sobre la justicia gratuita. Como una forma de demostrar la falta de uniformidad de las decisiones sobre el tema, se citarán las jurisprudencias de varios estados que difieren entre sí, causando incertidumbre legal a los litigantes, haciendo que los costos de los procedimientos se conviertan en un filtro impeditivo de acceso al poder judicial, lo que provoca, por lo tanto, un atentado al estado democrático.

PALABRAS CLAVE: Derecho de acción; Acceso a la justicia; Justicia gratuita; Hiposuficiencia.

\section{INTRODUÇÃO}

Nem sempre a lei é suficiente para garantir a eficácia do direito ou dever ali disposto. Muitas vezes o judiciário necessita da criação de outras leis, decretos, portarias, orientações, enfim, outros mecanismos para "colocar em prática" o que determinado artigo de lei dispõe. 
Um exemplo disto é o artigo $5^{\circ}$, inciso XXXV da Constituição Federal o qual prevê o exercício do Direito de Ação, como direito fundamental, contudo, para colocar o direito de Ação em prática se faz necessário muito mais do que a interpretação do texto, mas envolve estudo, discussão e criação de leis mais específicas sobre a forma de aplicação de referido artigo de lei.

Conforme abaixo será debatido, o Direito de Ação não se limita ao direito de propor uma ação, mas sim de acesso à justiça, permitindo aos cidadãos a busca pela tutela jurisdicional. Contudo, em razão de alguns impedimentos processuais, muitas vezes uma parcela da população tem enfrentado impedimentos ao livre acesso à justiça, como por exemplo, a necessidade de custear as custas processuais.

Neste artigo abordaremos o instituto da justiça gratuita e a ausência de parâmetros para definir os termos pobre/necessitado/hipossuficiente para aferição da real condição econômica do litigante e traremos jurisprudências recentes que demonstram os diferentes entendimentos dos juízes brasileiros sobre o tema.

\section{DIREITO DE AÇÃO E O ACESSO À JUSTIÇA}

\subsection{O conceito de direito de ação}

A Constituição Federal dispõe que "a lei não excluirá da apreciação do Poder Judiciário lesão ou ameaça a direito" (art. 5, XXXV). Trata-se, pois, da consagração constitucional do direito, princípio ou garantia de acesso ao Poder Judiciário (à justiça), da inafastabilidade da jurisdição ou da proteção judicial efetiva. (BRASIL, 1988) (2008):

Conforme leciona ilustríssimo doutrinador Luiz Rodrigues Wambier

Houve longa trajetória, no curso da história do Direito (e muito especialmente do direito processual civil), ao longo da qual contrapunham-se diversas concepções sobre o direito de ação. Hoje entende-se que ação é um direito público abstrato de requerer a tutela jurisdicional do Estado, para solução (útil) de determinada lide, foi conceito pacificamente aceito.

No mesmo sentido, assim entende Freddie Didier Junior (2017):

Direito de ação é o direito fundamental (situação jurídica, portanto) composto por um conjunto de situações jurídicas, que garantem ao seu titular o poder de acessar os tribunais e exigir deles uma tutela jurisdicional adequada, 
tempestiva e efetiva. É direito fundamental que resulta da incidência de diversas normas constitucionais, como os princípios da inafastabilidade da jurisdição e do devido processo legal $[\ldots]$.

Assim, apesar das diversas teorias e correntes doutrinárias que buscavam conceituar o que é (e era) o direito de ação, atualmente há um consenso sobre sua concepção, o qual é predominantemente processualista, apesar de ser um direito consagrado na Constituição Federal. (CRFB/1988)

Outro ponto que merece destaque é que o direito de ação não se limita à apreciação do judiciário, mas também garante ao cidadão que o processo seja justo, eficaz, de duração razoável, com amplo e irrestrito direito de defesa e contraditório.

Entretanto, apesar de o direito de ação consagrar e garantir ao cidadão o acesso ao Judiciário, muitas vezes, em nossa realidade fática, este mesmo cidadão que detém tal direito é impedido de exercê-lo em razão de impedimentos processuais e instrumentais ao propor uma ação, como por exemplo, o pagamento das custas processuais, gerando não somente uma restrição ao direito de propor uma ação, mas impactando no direito de acesso à justiça, conforme a diante veremos.

\subsection{O direito de ação como direito de acesso à justiça}

$\mathrm{Na}$ época dos Estados liberais burgueses, por direito de ação entendia-se apenas o direito formal de propor uma ação. Estaria em juízo quem pudesse suportar os custos de uma demanda, pois a desigualdade econômica e social não era objeto das preocupações do Estado. Bastava se proclamar o direito de ir a juízo, pouco importando se o titular do direito material lesado pudesse realmente se valer do direito de ação. (MARINONI, 2017)

Segundo Marinoni (2017):

O problema da "efetividade" do direito da ação, ainda que já fosse percebido no início do Século XX, tornou-se nítido quando da consagração constitucional dos chamados "novos direitos", ocasião em que a imprescindibilidade de um real acesso à justiça se tornou ainda mais evidente. Como adverte BOAVENTURA DE SOUZA SANTOS, os novos direitos sociais e econômicos, caso ficassem destituídos que fizessem impor o seu respeito, assumiriam a configuração de meras declarações políticas, de conteúdo e função mistificadores. Por isso logo se percebeu que a administração da justiça civil e os processos judiciais não mais poderiam ficar reduzidos a uma dimensão meramen- 
te técnica e socialmente neutra, devendo investigar-se as funções sociais por ele desempenhadas e, em especial, o modo como as opções técnicas no seu seio veiculam opções a favor ou contra interesses sociais divergentes ou mesmo antagônico.

É nesse contexto que faz sentido garantir a todos o direito constitucional de -verdadeiro- acesso à justiça que em primeiro momento pode parecer restringir-se, tão somente, ao direito de ação, de acesso ao Judiciário.

A expressão "acesso à justiça" é reconhecidamente de difícil definição, mas serve para determinar duas finalidades básicas do sistema jurídico o sistema pelo qual as pessoas podem reivindicar seus direitos e/ou resolver seus litígios sob os auspícios do Estado. Primeiro, o sistema deve ser igualmente acessível a todos; segundo, ele deve produzir resultados que sejam individual e socialmente justos. (CAPPELLETTI, 1988)

Desta feita, ao buscarmos garantir o livre exercício do Direito de Ação, necessário se faz que este direito alcance não somente a possibilidade de se propor uma demanda, mas também garante que o cidadão tenha o acesso e o direito à uma decisão justa, garantindo a eficácia daquele direito.

Entretanto, ainda que haja lei expressa que garanta o ingresso no âmbito judiciário, ainda encontramos impedimentos que obstam o exercício de referidos direitos, como, por exemplo, custos com advogado, custas processuais, sucumbência, ausência de segurança jurídica e decisões conflitantes.

Neste artigo falaremos apenas sobre as custas processuais como impedimento de exercício ao direito de ação e acesso à justiça.

\section{AS CUSTAS PROCESSUAIS COMO IMPEDIMENTO AO EXERCÍCIO DO DIREITO DE AÇÃO E ACESSO À JUSTIÇA}

O mais óbvio obstáculo para um efetivo acesso à justiça é o "custo do processo". Esse problema relaciona-se com o das custas judiciais devidas aos órgãos jurisdicionais, com as despesas para a contratação de advogado e com aquelas necessárias para a produção de provas. (MARINONI, 2017)

Ademais, o litigante, não só aquele sem poder aquisitivo, não ajuíza uma ação com receio de ser derrotado devido aos altos investimentos que são obrigados a dispor para demandar, ou seja, "quando o investimento no processo aparece aos olhos da pessoa como desproporcional ao proveito a postular e em face do risco assumido, ele constitui freio inibitório ao exercício da ação e possivelmente será mais um fator de permanência de insatisfação."(DINAMARCO, 2000)

Grande parte dos brasileiros tem os encargos financeiros de um pro- 
cesso como uma espécie de barreira ao acesso ao judiciário, pois esses custos (despesas com a produção de provas e as custas do processo, etc.) não poderão, sem que admitam complicado sacrifício de suas economias, ser tirados de seu orçamento familiar. (MARINONI, 2017)

Para tanto, a Constituição Federal, em seu art. $5^{\circ}$, LXXIV, promulgou o seguinte: Art. $5^{\circ}$ Todos são iguais perante a lei, sem distinção de qualquer natureza, garantindo-se aos brasileiros e aos estrangeiros residentes no País a inviolabilidade do direito à vida, à liberdade, à igualdade, à segurança e à propriedade, nos termos seguintes; LXXIV - o Estado prestará assistência jurídica integral e gratuita aos que comprovarem insuficiência de recursos ${ }^{3}$.

Não obstante a Constituição Federal prever a possibilidade de assistência judiciária, o judiciário brasileiro, ao se deparar com a questão de garantir o direito de ação e, ainda mais especificamente, o acesso à justiça, mas sem extinguir a necessidade de custeamento da máquina judiciária por meio da exigibilidade do pagamento de custas processuais criou a Lei 1060/50, a qual estabelece as normas para a concessão de assistência judiciária aos necessitados.

Referida Lei prevê que, aos necessitados nos termos da lei, será concedida a assistência judiciária gratuita, a qual compreende não somente a gratuidade das custas processuais, mas também dispõe que, a estes necessitados, haverá a nomeação de um curador especial, custeado pelo próprio Estado, para que a parte possa exercer seu direito com plenitude e garantido a assistência por um advogado.

Neste sentido, cumpre esclarecer que "assistência judiciária gratuita" $\left(\mathrm{CF}\right.$, art. $\left.5^{\circ}, \mathrm{LXXIV}\right)$, é um instituto de direito administrativo, posto à disposição do hipossuficiente como condição primeira para seu ingresso no judiciário, quando então, lhe é fornecido além das isenções de custas e atos processuais, também o defensor público. Já a "gratuidade de justiça", de menor abrangência, é um instrumento eminente processual que pode ser solicitado ao juiz da causa tanto no momento inaugural da ação quanto no curso da mesma, significando dizer que a dispensa das despesas processuais é provisória e condicionada à manutenção do estado de pobreza do postulante, podendo ser revogada a qualquer tempo. (PRUSSAK, 2016)

Contudo, citada lei se limitou a dizer que os beneficiários de tal benesse seriam os necessitados/pobres/hipossuficientes no termo da lei, sem fazer qualquer menção à quais parâmetros deveriam ser utilizados para caracterizar o

\footnotetext{
${ }^{3}$ Art. $1^{\circ}$. Os poderes público federal e estadual, independente da colaboração que possam receber dos municípios e da Ordem dos Advogados do Brasil, - OAB, concederão assistência judiciária aos necessitados nos termos da presente Lei. (Redação dada pela Lei ${ }^{\circ} 7.510$, de 1986). $§ 1^{\circ}$. Presume-se pobre, até prova em contrário, quem afirmar essa condição nos termos desta lei, sob pena de pagamento até o décuplo das custas judiciais.
} 
cidadão como necessitado/pobre/hipossuficiente nos termos da lei.

Inclusive, o artigo $1^{\circ}$ da Lei 9060/50 tem origem na redação dada pela Lei 7.510/86, lei esta que define como "pobre nos termos da lei" quem afirmar a condição mediante declaração nos termos da lei, não estabelecendo quaisquer parâmetros para que tal condição seja caracterizada, sendo que a declaração à que se refere só poderia ser questionada mediante impugnação ou quando houvesse elementos que levassem o juiz a questionar.

Ou seja, foi promulgada uma lei que garantia aos necessitados a assistência estatal para exercício do direito de ação e acesso à justiça, porém não houve conceituação do termo "pobre" ou necessitado, fazendo com que a interpretação deste termo ficasse a encargo do juiz da causa.

Com o advento do Código de Processo Civil de 2015, os artigos $2^{\circ}, 3^{\circ}$, $4^{\circ}, 6^{\circ}, 7^{\circ}, 11^{\circ}, 12^{\circ}$ e $17^{\circ}$ da Lei. $9060 / 50$ foram revogados, passando a vigorar o disposto nos arts. 98 e seguintes do CPC.

Ao tratar de Justiça gratuita, o CPC trouxe rol de despesas abarcadas na gratuidade de Justiça. $\mathrm{O} \S 1^{\circ}$ do artigo 98 tem nove incisos que elencam as principais despesas e custas processuais, como a indenização devida à testemunha, o custo do exame de DNA, os honorários de advogado, perito, intérprete ou tradutor, depósitos devidos para recursos, entre outros.

A presunção de veracidade da Declaração de Pobreza foi relativizada, sendo que, atualmente, os juízes têm exigido comprovantes dos mais variados tipos para verificarem se o postulante é beneficiário ou não da gratuidade da justiça.

Todavia, apesar de o Código Processual trazer mudanças significativas na justiça gratuita, com enfoque na gratuidade das custas processuais, o conceito e/ou parâmetros foram novamente deixados de lado pelo legislador, permanecendo aos juízes a responsabilidade e liberdade de definir quem é ou não é beneficiário de referida benesse.

Por tais razões, vemos na prática, a dificuldade de se chegar à um consenso e definir, de fato, quem tem direito à justiça gratuita, haja vista que o crivo subjetivo do julgador é inconstante e, mesmo STJ e STF não possuem um parâmetro ou critérios a serem analisados para se chegar à um acordo sobre os meios de se auferir a hipossuficiência de uma pessoa.

Cumpre frisar que concessão do benefício da Justiça Gratuita deve orientar-se pelo estímulo ao jurisdicionado em promover seus direitos; jamais, em atemorizá-lo com eventuais duras consequências na promoção da demanda. O direito de ação é constitucionalmente resguardado; e constitui princípio geral de direito a garantia de acesso ao Judiciário.

A seguir veremos jurisprudências atuais e mostraremos alguns casos concretos de como há discrepância no entendimento do judiciário. 


\section{DOS CASOS CONCRETOS DE DIVERGÊNCIA JURISPRUDENCIAL SOBRE OS PARÂMETROS DE CONCESSÃO DO BENEFÍCIO DA JUSTIÇA GRATUITA}

Considerando que a lei não dispõe de parâmetros concretos para que seja feita uma análise justa de quem poderá ser beneficiário das benesses concedidas pelo CPC e CF, o que se é a mais ampla de gamas de jurisprudência, totalmente distintas entre si, gerando uma insegurança jurídica.

Por exemplo, o STJ neste corrente ano (BRASIL, 2019):

PROCESSUAL CIVIL. PREVIDENCIÁRIO. RENDA INFERIOR AO CRITÉRIO OBJETIVO. NECESSIDADE DE ESTUDO DO CASO E VERIFICAÇÃO DAS REAIS CONDIÇÕES SOCIAIS E ECONÔMICAS DE CADA CANDIDATO À BENEFICIÁRIO. PRETENSÃO DE REEXAME FÁTICO PROBATÓRIO. INCIDÊNCIA DO ENUNCIADO N. 7 DA SÚMULA DO STJ. I - Na origem, trata-se de ação ajuizada em desfavor do INSS - Instituto Nacional do Seguro Social, visando à condenação ao pagamento de benefício assistencial. Narra a inicial que a autora é idosa e que a renda de sua família é insuficiente. Assim, pugnou pela concessão do benefício. Na sentença, julgou-se improcedente o pedido. No Tribunal a quo, a sentença foi mantida. II - A questão controversa dos autos diz respeito, basicamente, em saber se aferido o critério objetivo de renda inferior a 1/4 do salário mínimo, o benefício assistencial, atendido os demais requisitos, deve ser deferido. III - Trata-se de pessoa idosa, cuja renda, excluída a de seu esposo, por força do art. 34 da Lei n. 10.741/03, é inferior ao critério objetivo. Contudo, as instâncias ordinárias, em razão da análise do parecer sócio-econômico, concluíram ausente a miserabilidade, tendo em vista a morada em habitação própria, bem como o cuidado recebido pelos familiares próximos. IV - Sabe-se que o critério objetivo da renda salarial não tem sido considerado parâmetro confiável para se aferir a miserabilidade dos postulantes ao benefício assistencial. $V$ - Do mesmo modo que a renda superior a 1/4 do salário mínimo per capita muitas vezes não afasta a situação de miserabilidade. Uma renda inferior a este critério objetivo não quer dizer, necessariamente, que o indivíduo encontra-se em situação de miserabilidade. VI - Há julgado da sessão plenária do 
Supremo Tribunal Federal que enfrenta essa questão dispondo que "a definição dos critérios a serem observados para a concessão do benefício assistencial depende de apurado estudo e deve ser verificada de acordo com as reais condições sociais e econômicas de cada candidato à beneficiário, não sendo o critério objetivo de renda per capta o único legítimo para se aferir a condição de miserabilidade". Nesse sentido: Rcl n. 4154 AgR, Relator (a): Min. Dias Toffoli, Tribunal Pleno, julgado em 19/9/2013, Acórdão Eletrônico DJe-229 Divulg 20/11/2013 Public 21/11/2013. VII - No Superior Tribunal de Justiça, igualmente, tem-se entendido que o critério objetivo pode ser afastado quando, por outros meios, for possível aferir a ausência de miserabilidade do postulante, cuja revisão é, ainda, inviável em via de recurso especial ante o óbice constante da Súmula n. 7/STJ. VIII - Agravo interno improvido. (STJ - AgInt no AREsp: 907081 SP 2016/0102678-7, Relator: Ministro FRANCISCO FALCÃO, Data de Julgamento: 11/04/2019, T2 - SEGUNDA TURMA, Data de Publicação: DJe 03/05/2019) (grifo nosso)

O Tribunal de Justiça do Rio Grande do Sul entende que o parâmetro para concessão da justiça Gratuita é até 05 salários mínimos, conforme abaixo (RIO GRANDE DO SUL, 2018):

AGRAVO DE INSTRUMENTO. FAMÍLIA. DIVÓRCIO. PEDIDO DE AJG. CABIMENTO. RENDA INFERIOR A 5 SALÁRIOS MÍNIMOS. Para a concessão do benefício da Assistência Judiciária Gratuita, mostra-se necessária prova da hipossuficiência econômica da parte, não bastando, para tanto, a mera declaração de pobreza. Como se depreende do caso em apreço o agravante percebe remuneração mensal inferior a cinco salários mínimos, patamar utilizado por este Tribunal de Justiça para a concessão do benefício, de modo que o demonstrativo de pagamento acostado aos autos permite a concessão do benefício, uma vez que caracterizada a indisponibilidade econômica. RECURSO PROVIDO. (Agravo de Instrumento $N^{\circ} 70080222888$, Sétima Câmara Cível, Tribunal de Justiça do RS, Relator: Liselena Schifino Robles Ribeiro, Julgado em 18/12/2018). (TJ-RS - AI: 70080222888 RS, Relator: Liselena Schifino Robles Ribeiro, Data de Julgamento: 18/12/2018, Sétima 
Câmara Cível, Data de Publicação: Diário da Justiça do dia $18 / 01 / 2019$ )

O Tribunal de Justiça do Rio de Janeiro, entende que, mesmo que a pessoa tenha bens, o que vale é o rendimento para averiguação da situação de hipossuficiência (RIO DE JANEIRO, 2019):

AGRAVO DE INSTRUMENTO. GRATUIDADE DE JUSTIÇA. AUSÊNCIA DE COMPROVAÇÃO. INDEFERIMENTO. MAIOR DE 60 (SESSENTA) ANOS DE IDADE. RENDA LÍQUIDA MENSAL INFERIOR A 10 (DEZ) SALÁRIOS MÍNIMOS. ISENÇÃO DO PAGAMENTO DAS CUSTAS PROCESSUAIS COM BASE NO ARTIGO 17, X, DA LEI 3.350/99. 1. A afirmação de pobreza goza tão somente de presunção relativa de veracidade, sendo facultado ao juiz exigir a comprovação da alegada insuficiência de recursos. Verbete $n^{\circ} 39$ da Súmula deste Egrégio Tribunal. 2. Compulsando-se os autos, verifica-se que a agravante possui dois imóveis próprios, um no qual reside e outro que complementa sua renda com os alugueres, que em maio de 2017 estava alugado ao valor de $\mathrm{R} \$ 1.800,00$ (hum mil e oitocentos reais), o que denota ser um imóvel de alto padrão na cidade. 3 . Além disso, verifica-se da declaração do imposto de renda juntada aos autos, do exercício 2018, que a recorrente é empresária e, ainda, declara que possui em seu poder a quantia de $\mathrm{R} \$ 75.000,00$ (setenta e cinco mil reais). 4. Desse modo, não há como agasalhar a pretensão recursal, pois a parte recorrente não se inclui no conceito de hipossuficiente para os fins pretendidos. 5. Entretanto, a agravante faz jus à isenção das custas processuais, em razão do disposto no artigo 17, X, da Lei Estadual n $n^{0} 3.350 / 99$, que é taxativo neste sentido e não condiciona a concessão da isenção ao cumprimento de qualquer outro requisito e tampouco à análise do panorama financeiro do litigante. 6 . Deveras, a recorrente conta com 63 (sessenta e três) anos (000023) e, nos termos do documento de fl. 100 (000100) dos autos principais, seus ganhos mensais correspondem ao valor de $\mathrm{R} \$ 2.158,35$ (dois mil, cento e cinquenta e oito reais e trinta e cinco centavos), que se mostra abaixo do limite legal (10 salários mínimos). 7. Dessa forma, faz jus a demandante à isenção pleiteada. A benesse, contudo, não abrange a taxa judiciária, que ostenta natureza jurídica tributária e não de custas processuais. 8. Recurso pro- 
vido em parte. (TJ-RJ - AI: 00135690520198190000 , Relator: Des(a). JOSÉ CARLOS PAES, Data de Julgamento: 22/05/2019, DÉCIMA QUARTA CÂMARA CÍVEL).

$\mathrm{Na}$ mesma linha de raciocínio do TJRJ, entende-se que a Lei que trata do benefício, não exige que o requerente seja miserável para que possa ser considerado hipossuficiente, mas sim que o pagamento das custas prejudique o seu sustento ou de sua família.

Nesse sentido, em feliz decisão, o Meritíssimo Juízo da $2^{\mathrm{a}}$ Vara Cível do Foro Regional de Santana da Comarca de São Paulo (SP), em incidente de impugnação à concessão dos benefícios da justiça gratuita autuado sob o ${ }^{\circ}$ 0833427-45.2006.8.26.0001, considerou que:

[...] o ordenamento jurídico não exige estado de miserabilidade ou de indigência, para que alguém receba os benefícios, nem mesmo que aliene imóvel próprio, em que resida, ou outros bens, para dispor de recursos (liquidez) e, assim, suportar as despesas, os gastos de um processo. [...]

Não é e nem parece justo exigir que o postulante venda seus bens para custear um processo, muito menos que o mesmo esteja em estado de miserabilidade para conseguir a concessão dos benefícios da justiça gratuita. O que deve ser analisado não é somente os rendimentos, mas a inflação, se a pessoa possui dependentes, quanto é o custo de vida de um cidadão comum, não apenas o miserável.

\section{CONCLUSÃO}

Consoante o acima exposto e levando-se em conta os inúmeros casos já presenciados por esta Autora, nos quais, o judiciário, sem qualquer fundamentação coerente nega o benefício, encontramo-nos em uma situação de instabilidade jurídica.

Isto porque, muitas pessoas evitam acionar o poder judiciário para obter um direito que acreditam ter e acabam, muitas vezes, por serem lesados ou gravemente ameaçados de lesão. Mas até que ponto os rendimentos financeiros, em um país que tem um dos maiores impostos do mundo deve ser sobreposto ao direito de acionarmos o judiciário?

$\mathrm{O}$ acesso à justiça deve prevalecer quando há dúvidas sobre os rendimentos, para que não haja cerceamento de algo que todos clamamos, que é a justiça. 


\section{REFERÊNCIA}

BRASIL. Constituição da República Federativa do Brasil de 1988. Disponível em: http://www.planalto.gov.br/ccivil_03/constituicao/constituicao.htm. Acesso em: 04 set. 2019.

BRASIL. Código de Processo Civil. Lei n ${ }^{\circ}$ 13.105, de 16 de Março de 2015. Disponível em: http:/www.planalto.gov.br/ccivil_03/_ato2015-2018/2015/lei/ 113105.htm. Acesso em: 04 set. 2019.

BRASIL. Superior Tribunal de Justiça (STJ). STJ AgInt no AREsp: 907081 SP 2016/0102678-7, Relator: Ministro Francisco Falcão, Data de Julgamento: 11/04/2019, T2 - Segunda Turma, Data de Publicação: DJe 03/05/2019- Disponível em: https://stj.jusbrasil.com.br/jurisprudencia/719590359/agravo-interno-no-agravo-em-recurso-especial-agint-no-aresp-1398985-pb-2018-0300551-8. Acesso em: 10. set. 2019.

CAPPELLETTI, Mauro. Acesso à justiça. Tradução de Ellen Graie Northfleet. Porto Alegre: Fabris. 1988.

DIDIER JUNIOR, Freddie; Curso de Direito Processual Civil. 19. ed. Editora JusPODIVM, 2017.

DINAMARCO, Cândido Rangel. A instrumentalidade do processo. 8. ed. São Paulo: Malheiros, 2000.

MARINONI, Luiz Guilherme; Curso de Processo Civil. v. 1. 3. ed. São Paulo: Revista dos Tribunais, 2017.

PRUSSAK, Jucineia. Justiça Gratuita no novo CPC. Jusbrasil, 2016. Disponível em: https://jucineiaprussak.jusbrasil.com.br/noticias/326132115/justica-gratuita-no-novo-cpc. Acesso em: 05. set. 2019.

RIO GRANDE DO SUL. Tribunal de Justiça do Rio Grande do Sul (TJRS). TJRS - AI: 70080222888 RS, Relator: Liselena Schifino Robles Ribeiro, Data de Julgamento: 18/12/2018, Sétima Câmara Cível, Data de Publicação: Diário da Justiça do dia 18/01/2019. Disponível em: https://tj-rs.jusbrasil.com.br/jurisprudencia/664612448/agravo-de-instrumento-ai-0080222888-rs?ref=serp. Acesso em: 10. set. 2019.

RIO DE JANEIRO. Tribunal de Justiça do Rio de Janeiro (TJRJ). TJRJ-AI: 
00135690520198190000, Relator: Des. JOSÉ CARLOS PAES, Data de Julgamento: 22/05/2019, Décima Quarta Câmara Cível. Disponível em: https:// tj-rj.jusbrasil.com.br/jurisprudencia/713074550/agravo-de-instrumento-ai-5690520198190000?ref=serp. Acesso em: 10. set. 2019.

WAMBIER, Luis Rodrigues. Curso Avançado de Processo Civil. v. 1. 10. ed. São Paulo: Revista dos Tribunais, 2008. 